\title{
FINANCEIRIZAÇÃO DAS COMMODITIES AGRÍCOLAS E ECONOMIA DO AGRONEGÓCIO NO BRASIL: NOTAS SOBRE SUAS IMPLICAÇÕES PARA O AUMENTO DOS CONFLITOS PELA TERRA*
}

\author{
Recebido: 19 de junho de 2018 • Aprovado: 22 de novembro de 2018 \\ https://doi.org/10.22395/seec.v22n50a5 \\ Fernando Michelotti** \\ Hipólita Siqueira**
}

\section{RESUMO}

\begin{abstract}
A articulação entre financeirização das commodities e a corrida global por terras constitui um importante objeto de reflexão no debate contemporâneo. Esses movimentos têm sido associados a processos múltiplos que vão desde o aumento da demanda chinesa por matérias-primas à apropriação de terras em países com abundância em recursos naturais na América Latina e na África. Com ênfase nas implicações desses processos no Brasil, o objetivo deste artigo é identificar as relações entre as dinâmicas econômicas sistêmicas e a configuração de uma economia do agronegócio e suas implicações para o aumento dos conflitos territoriais e o agravamento da questão fundiária. A metodologia consiste em revisão crítica da literatura e análise de informações institucionais. O artigo destaca que a maior complexidade do regime de acumulação contemporâneo está associada à intensa apropriação territorial e à ampliação de conflitos fundiários no Brasil.
\end{abstract}

\section{PALAVRAS-CHAVE}

Financeirização das commodities; economia do agronegócio; conflitos territoriais; Brasil.

\section{CLASSIFICAÇÃ̃ JEL}

\author{
Q14, Q15
}

\section{CONTEÚDO}

Introdução; 1. Regime de Acumulação, Financeirização das Commodities e economia do agronegócio; 2. Economia do agronegócio, expansão da produção agropecuária e agravamento da questão fundiária; 3. Conclusões; Bibliografia.

\footnotetext{
Artigo resultante de reflexões e pesquisas em andamento realizadas no âmbito do grupo de pesquisa CNPq "Espaço e Poder", do qual os autores fazem parte.

. Engenheiro Agrônomo, Universidade de São Paulo, São Paulo, Brasil. Mestre em Planejamento do Desenvolvimento, Universidade Federal do Pará, Belém, Brasil. Doutorando em Planejamento Urbano e Regional, Universidade Federal do Rio de Janeiro, Rio de Janeiro, Brasil. Pesquisador, Grupo de Pesquisa Espaço e Poder, CNPq, Brasil. Professor, Instituto de Estudos do Desenvolvimento Agrário e Regional, Universidade Federal do Sul e Sudeste do Pará, Marabá, Brasil. E-mail: michelotti.f@gmail.com

... Economista, Universidade Federal de Uberlândia, Uberlândia, Brasil. Mestre e Doutora em Desenvolvimento Econômico, Universidade Estadual de Campinas, Campinas, Brasil. Pesquisadora, Grupo de Pesquisa Espaço e Poder, CNPq, Brasil. Professora, Instituto de Pesquisa em Planejamento Urbano e Regional, Universidade Federal do Rio de Janeiro, Rio de Janeiro, Brasil. E-mail: hipolitaufrj@gmail.com
} 


\title{
FINANCIERIZACIÓN DE LAS COMMODITIES AGRÍCOLAS Y ECONOMÍA DEL AGRONEGOCIO EN BRASIL: NOTAS SOBRE SUS IMPLICACIONES PARA EL AUMENTO DE LOS CONFLICTOS POR LA TIERRA
}

\begin{abstract}
RESUMEN
La articulación entre financierización de las commodities y la corrida global por las tierras constituye un importante objeto de reflexión en el debate contemporáneo. Esos movimientos han sido asociados a procesos múltiples que van desde el aumento de la demanda de China por materias primas hasta la apropiación de tierras en países con abundancia en recursos naturales en América Latina y en África. Con énfasis en las implicaciones de dichos procesos en Brasil, el objetivo de este artículo es identificar las relaciones entre las dinámicas económicas sistémicas y la configuración de una economía del agronegocio y sus implicaciones para el aumento de los conflictos territoriales y el agravamiento de la cuestión agraria. La metodología consiste en revisión crítica de la literatura y análisis de informaciones institucionales. El artículo destaca que la principal complexidad del régimen de acumulación contemporáneo está asociada a la intensa apropiación territorial y a la ampliación de conflictos agrarios en Brasil.
\end{abstract}

PALABRAS CLAVE

Financierización de las commodities; economía del agronegocio; conflictos territoriales; Brasil.

CLASSIFICACIÓN JEL

Q14, Q15

\section{FINANCIALIZATION OF AGRICULTURAL COMMODITIES AND AGRIBUSINESS ECONOMICS IN BRAZIL: NOTES ON ITS IMPLICATIONS FOR THE RISE OF LAND CONFLICTS}

\begin{abstract}
The articulation between commodities financialization and the global race for lands is an essential object of reflection in the contemporary debate. These movements have been associated with multiple processes ranging from the increased Chinese demand for raw materials to land grabbing in countries with abundant natural resources in Latin America and Africa. With an emphasis on the implications of these processes in Brazil, this article aims at identifying the relations between the systemic economic dynamics and the configuration of an agribusiness economy and its implications for the increase of territorial conflicts and the worsening of the land issue. The methodology consists of a critical review of the literature and analysis of institutional information. The article highlights that the greater complexity of the regime of contemporary accumulation is associated with intense territorial appropriation and the expansion of land conflicts in Brazil.
\end{abstract}

\section{KEYWORDS}

Financialization of commodities; agribusiness economics; territorial conflicts; Brazil.

JEL CLASSIFICATION

Q14, Q15 
Financeirização das commodities agrícolas e economia do agronegócio no Brasil: notas sobre suas implicações para o aumento...

\section{INTRODUÇÃO}

Ao longo dos governos progressistas comandados pelo Partido dos Trabalhadores (PT) no Brasil, entre 2003 e 2014, os conflitos agrários apresentaram dois movimentos gerais: uma elevação abrupta nos anos iniciais seguida de queda até o ano 2008, quando voltaram a apresentar tendência ascendente até 2014. A elevação inicial está relacionada à mobilização popular, especialmente por meio de ocupações de terra, ligada às expectativas de avanço de uma reforma agrária persistentemente adiada na história brasileira. No entanto, tais expectativas foram frustradas pela predominância de políticas de combate à pobreza durante esses governos que não alteraram a estrutura fundiária. Se essas políticas explicam a tendência de redução dos conflitos agrários até 2008, como interpretar seu novo crescimento após esse período?

Um dos aspectos que pode contribuir com a análise desse quadro é a relação entre a expansão da produção de commodities impulsionada por processos de financeirização, aumento da demanda chinesa e a chamada corrida por terras. Essa expansão fortaleceu a economia do agronegócio que, para além de se constituir como uma frente de acumulação, atua como pacto político em torno da grande propriedade e da apropriação de terras, com tendência a agravar os conflitos territoriais. Nessa perspectiva, este artigo propõe articular, de modo exploratório, elementos que permitam identificar relações entre dinâmicas econômicas sistêmicas e a consolidação da economia do agronegócio e suas implicações para o agravamento da questão fundiária no Brasil.

Além desta introdução e das considerações finais, o artigo está dividido em duas seções. Na primeira, foram examinadas algumas dimensões do debate teórico sobre o regime de acumulação contemporâneo e, em seguida, foi dada ênfase às mudanças recentes no mercado agroalimentar mundial com a intensificação de dinâmicas vinculadas ao processo de financeirização, bem como à configuração da economia do agronegócio no Brasil. Na segunda seção, foi examinada a economia do agronegócio brasileiro, a expansão da produção agrícola e suas implicações para a complexificação da questão agrária e dos conflitos pela terra em regiões de maior relevância na produção de commodities no país.

\section{REGIME DE ACUMULAÇÃO, FINANCEIRIZAÇÃO DAS COMMODITIES E ECONOMIA DO AGRONEGÓCIO}

A emergência de um "regime de acumulação dominado pelas finanças", na elaboração de Chesnais (2005), ou de um "capitalismo dirigido pelas finanças", na elaboração de Guttmann (2016), tem sido caracterizada pela intensificação da submissão do sistema 
econômico contemporâneo aos imperativos da lógica da acumulação financeira, ou ainda, pelas motivações financeiras dos agentes econômicos.

Para Guttmann (2016), o "capitalismo dirigido pelas finanças" se configura a partir da introdução de mecanismos específicos, sob o comando de agentes econômicos, tais como fundos institucionais (fundos de hedge e fundos de pensão) e bancos. Entre os principais mecanismos, estão: a transição do financiamento por meio do endividamento bancário (finanças indiretas) para o financiamento através de valores mobiliários (derivativos) e da emissão de ações ou emissão de títulos (finanças diretas); o aumento da participação de ativos financeiros no patrimônio das empresas; a introdução de inovações financeiras à sombra da regulação dos bancos centrais; a imposição de uma governança corporativa cujo objetivo é a maximização do valor das ações; a ausência de controles efetivos do sistema financeiro internacional; a desregulamentação dos sistemas financeiros nacionais e a autorregulação dos agentes.

Em sua dimensão histórico-espacial, a emergência de uma dinâmica capitalista financeirizada remonta a processos mais amplos deflagrados a partir dos anos 1970. Com base nas análises de Harvey (2005, 2008a, 2008b), três aspectos podem ser enfatizados: 1) os limites do regime de acumulação fordista nos países de capitalismo avançado levaram a uma restauração do poder de classe das elites capitalistas, com base em inovações tecnológicas e mudanças organizacionais da produção e do trabalho industrial e a dominação financeira; 2) a instabilidade e a volatilidade da acumulação capitalista, com intensificação da frequência de crises de sobreacumulação, que deflagraram ajustes espaço-temporais e uma crescente acumulação por espoliação; 3) a legitimação desses processos através do fortalecimento ideológico de comportamentos e concepções mentais baseadas em narrativas do neoliberalismo e da globalização.

Para esse autor, a dominação financeira mostrou se como a principal solução para a dificuldade crescente em sustentar uma taxa de acumulação ampliada necessária para a manutenção do sistema. No entanto, a circulação financeira gera uma grande quantidade de capital fictício excedente que força a criação de novos espaços geográficos e econômicos de aplicação rentável. A partir dessa perspectiva, verifica-se a retomada de velhos mecanismos de acumulação primitiva, assim como a criação de novos dispositivos que vão desde a biopirataria até as privatizações, voltadas para a mercantilização de bens comuns. A associação de poderes territoriais e capitalistas, denominados por Harvey (2005) de "novo imperialismo", com utilização de diferentes instrumentos de poder que garantem a dominação de terras e seus recursos, é parte, portanto, desse contexto mais amplo. 
Financeirização das commodities agrícolas e economia do agronegócio no Brasil: notas sobre suas implicações para o aumento...

Em outra vertente, Sassen (2016) argumenta que a complexidade das economias contemporâneas pode ser compreendida de modo mais aprofundado como um sistema de expulsão. Ao analisar processos de financeirização, intensificação do endividamento privado e público, bem como o land grabbing, essa autora destaca as lógicas sistêmicas dos deslocamentos forçados, evasões fiscais, aumento das desigualdades de renda, apropriação e devastação de terras comuns e as destruições dos corpos hídricos.

Apesar das várias abordagens, a centralidade sistêmica dos agentes do mercado de derivativos é consensual. Além da magnitude do volume de operações, Carneiro et al. (2011) ressaltam a hegemonia desse mercado na valorização da riqueza capitalista, tendo em vista seu papel crucial na formação de preços, o que subordina os demais às pressões de operações especulativas. A partir dessa perspectiva de complexidade e instabilidade sistêmica, para Carneiro et al. (2011, p. 7)

(...) quanto mais voláteis são as variáveis econômicas que afetam a produção de bens e serviços, mais importantes são os derivativos. Entretanto, a análise da importância dos derivativos torna-se mais complexa quando se admite a possibilidade do próprio mercado de derivativos ampliar a instabilidade dos preços macroeconômicos. Em outras palavras, eles podem resolver problemas de eficiência microeconômicos e agravar problemas de instabilidade macroeconômica.

No que se refere ao mercado mundial agroalimentar, o regime dominado pelas finanças tem implicações significativas. Durante os anos 1980 e 1990 e após a crise das empresas ponto.com no início dos anos 2000 e do subprime nos Estados Unidos em 2007/2008, as lógicas especulativas têm predominado nos mercados das commodities minerais e agrícolas. Isso levou a uma elevação sem precedentes dos preços e pressionou o aumento de salários e custos industriais com matérias-primas, o que configurou um círculo vicioso que reduziu ainda mais a rentabilidade industrial e fortaleceu a financeirização. Nesse contexto, para Rubio (2015), não seriam mais os problemas conjunturais de quebra de safra ou de aumento de demanda dos produtos que explicariam a elevação de preços, mas, sobretudo, o movimento do capital especulativo que se aproveita dessas incertezas conjunturais e fragilidades do sistema agroalimentar na busca de rentabilidade financeira.

Para essa autora, tanto as crises como o movimento mais geral de elevação de preços beneficiam apenas os produtores rurais que operam em larga escala e com alto padrão tecnológico e as empresas agroalimentares transnacionais. Essas empresas são as maiores beneficiadas nesse processo (empresas de insumos, maquinário, comercialização e processamento), pois impõe preços internos aos produtores rurais que, muitas vezes, não refletem os aumentos do mercado mundial, e assim se apropriam dessa diferença. 
Sobre o processo de financeirização das commodities, em especial o mercado de derivativos das commodities agrícolas, Kerckhoffs, van Os e Vander (2010) analisam as relações entre os mercados de futuros, os especuladores e a determinação dos preços de comercialização nos mercados à vista. No período da criação dos primeiros mercados de futuro, o objetivo era dar maior estabilidade à comercialização de alimentos por meio de um acordo de compra e venda de certa quantidade de produto, por certo preço, em uma data futura, para facilitar o planejamento da produção e distribuir os riscos entre todos os atores envolvidos. Entretanto, a partir dos anos 1970, foram introduzidas mudanças nas regras de funcionamento desses mercados o que gerou flexibilizações importantes, tais como a possibilidade de compra e venda dos títulos futuros antes da entrega final do produto. Com isso, passaram a atrair especuladores como fundos de hedge, fundos de pensão, investidores institucionais e bancos de investimentos.

A comercialização desses contratos futuros tem se dado através dos mercados de derivativos, e muitas dessas transações entram em cestas em conjunto com outros tipos de commodities, de produtos e títulos, e são negociadas a partir de um índice mais amplo. Assim, no mesmo mercado coexistem interesses e estratégias distintas, por exemplo, atores diretamente envolvidos na cadeia produtiva procurando se proteger das flutuações de preços, especuladores que apostam na flutuação positiva da commodity em questão e aqueles que adotam um fator de baixo risco em uma cesta diversificada de derivativos. Toda essa complexa rede de mecanismos de apostas financeiras relacionadas às commodities leva a situações em que os preços desses títulos podem ser negociados em valores mais elevados do que os valores reais da produção, o que pressiona não apenas seus preços futuros, mas também os próprios preços praticados à vista que, por sua vez, desencadeiam o aumento de áreas plantadas.

O boom dos preços verificado entre 2000 e 2014 impulsionou uma forte expansão da produção das commodities em vários países emergentes, entre eles, os países do Brics, e isso levou ao aumento da competição no mercado agroalimentar, à perda de posição hegemônica dos EUA e à ampliação de excedentes redirecionados aos agrocombustíveis (Rubio, 2015). O Gráfico 1 demonstra a alta de preços das commodities, com um comportamento bastante similar de todas elas. Para Flexor e Leite (2017), essa dinâmica não pode ser considerada apenas um simples reflexo da demanda por um ou alguns produtos, pois também está vinculada à atuação de processos mais gerais de financeirização. Nesse sentido, haveria tendências de formação de bolhas especulativas que, em algum momento, estouram, como se verifica na queda iniciada em 2011/2012 e agravada em 2014/2015. 
Financeirização das commodities agrícolas e economia do agronegócio no Brasil: notas sobre suas implicações para o aumento...

Gráfico 1. Índice de preços de commodities (2005 = 100)

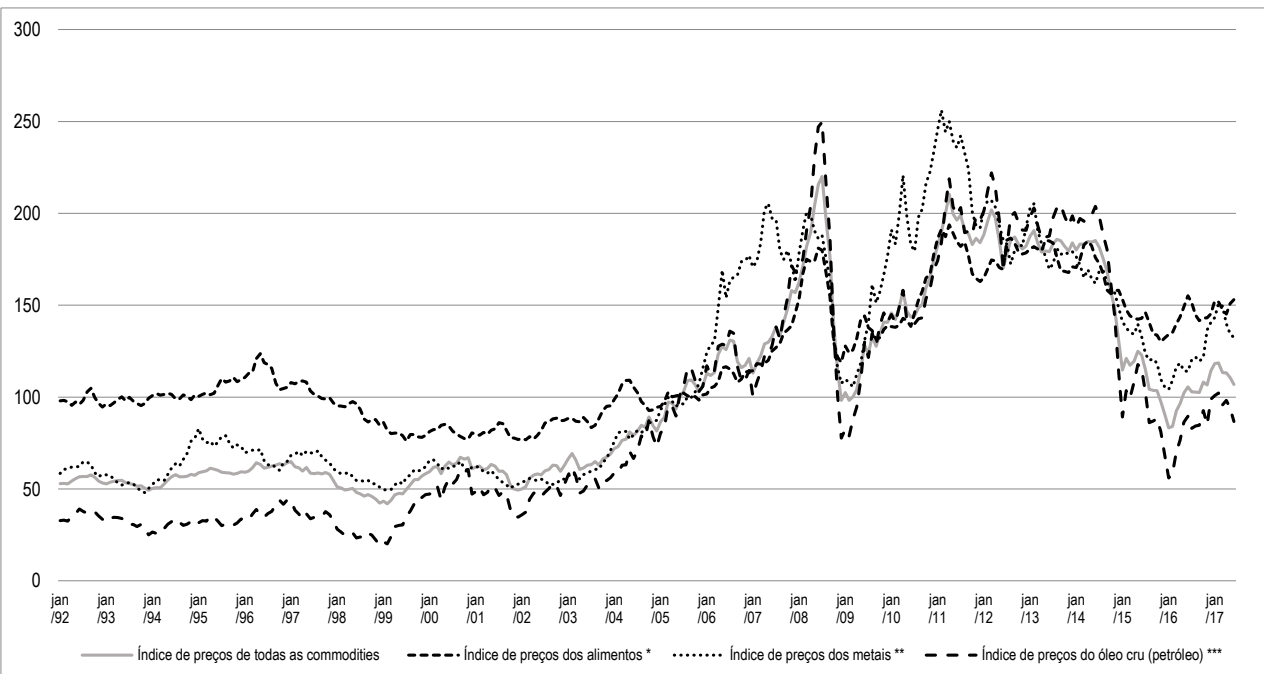

Notas: * Inclui índices de preços de cereais, óleos vegetais, carne, frutos do mar, açúcar, banana e laranja

". Inclui índices de preços de cobre, alumínio, minério de ferro, estanho, níquel, zinco, chumbo e urânio

"** Média simples dos preços de Dated Brent, West Texas Intermediate e Dubai Fateh

Fonte: elaboração dos autores a partir de Flexor e Leite (2017) e dados do IMF Primary Commodity Prices (monthly data).

Há várias abordagens possíveis e necessárias para a análise das relações entre financeirização e produção de commodities, em especial, ao considerar os ciclos de preços internacionais e os rearranjos no sistema agroalimentar mundial. No que se refere ao caso brasileiro, é necessário inserir esse processo em um contexto mais geral de mudança na estratégia de acumulação que se iniciou na década de 1990 e, segundo Paulani (2008), levou o país a se transformar em uma "plataforma de valorização financeira" e configurou assim novas relações de dependência. O Estado cumpre um papel-chave nessa transformação, e atua, simultaneamente, como produtor e garantidor de capital fictício através de transferências de parcelas de rendas reais para a esfera da valorização financeira. Entre as várias iniciativas voltadas a promover uma reorganização institucional e os ajustes macroeconômicos que assegurem essa transferência, o estímulo à exportação de commoditites tem sido central como tentativa de equilibrar a balança de pagamentos diante da necessidade crescente de remuneração do capital aportado no país.

Como resposta a essas transformações do país, em uma conjuntura favorável no mercado internacional, configurou-se uma economia do agronegócio que, para 
Delgado (2012, p. 91), exprime a integração de capitais na agricultura através de complexos agroindustriais, mercado de terras e sistema de crédito rural. Segundo esse autor, o processo de acumulação no agronegócio também assume características de um pacto de economia política, compreendido como "organização dos interesses hegemônicos de classes sociais no interior do aparelho do Estado" (p. 91). Representa, portanto, um pacto de economia política entre complexos agroindustriais, grande propriedade fundiária e o Estado, em associação "para captura do excedente econômico e particularmente da renda fundiária agrícola e mineral" (Delgado, 2012, p. 93).

Durante o segundo governo de Fernando Henrique Cardoso (1999-2002), a estratégia do agronegócio surgiu como alternativa para a geração de saldos comerciais capazes de suprir os déficits do balanço de pagamentos gerados com as crescentes saídas de rendas de capital e consequentes perdas de reservas internacionais. Para Delgado (2012), os ajustes conjunturais nesse período foram levando ao desmonte da política anterior de modernização conservadora da agricultura e a uma nova estratégia de acumulação de capital no setor agrícola, o que estruturou uma economia do agronegócio.

Segundo esse autor, cinco iniciativas foram importantes: i) investimento em infraestrutura para incorporação de novos territórios, segundo uma política de "eixos de integração e desenvolvimento"; ii) redirecionamento da pesquisa agropecuária para operar em sincronia com as multinacionais do agronegócio; iii) fraca regulação do mercado de terras; iv) mudança na política cambial para tornar o agronegócio competitivo no cenário internacional e v) reativação do crédito rural no âmbito dos "planos safra".

Essa estratégia foi continuada e reforçada nos governos de Luiz Inácio Lula da Silva, nos quais houve vigorosos saldos comerciais, entre 2003-2007. Isso ocorreu em função da maturação das mudanças do governo anterior e seus efeitos na rearticulação de alguns complexos agroindustriais e minerais, bem como da quadra favorável de preços internacionais das commodities.

No período lulista, o crescimento econômico brasileiro' foi liderado, em grande parte, pelo aumento das exportações, por sua vez, dinamizadas pela abundância da liquidez internacional e pelo boom de preços das commodities agrícolas e minerais (soja, minério de ferro, petróleo etc.), sendo muito destacado pela literatura o efeito

China. Entre os determinantes desse boom, estiveram não apenas os componentes

' Segundo IBGE/Contas Nacionais, nesse período, as taxas de crescimento econômico foram positivas e superiores às do período 1980-02 (cerca de $2 \%$ a.a.). Entre 2004-2008, a economia nacional cresceu a uma taxa média anual de cerca de $5 \%$ e apresentou em 2009, como reflexo da crise externa, um decrescimento de $0,1 \%$. 
Financeirização das commodities agrícolas e economia do agronegócio no Brasil: notas sobre suas implicações para o aumento...

financeiros e especulativos, destacados pela literatura sobre financeirização dos preços das commodities, mas também o papel hegemônico que a China (grande demandante de matérias-primas, insumos energéticos e proteínas alimentares) vem exercendo como potência global. Nesse contexto, foram mobilizadas economias de países com abundância em terras e recursos naturais, sobretudo da América Latina e da África. O superávit comercial do Brasil com a China aumentou de US\$ 2,6 bilhões em 2001 para US\$ 46 bilhões em 2006. O período entre 2007 e 2013 foi de redução do superávit, mas no ano de 2014 houve déficit comercial. Porém, em 2016, o superávit comercial voltou ao mesmo patamar de 2006 e atingiu cerca de US\$ 67 bilhões em 2017. Entre os principais produtos de exportação, 25,12 \% foram de grãos de soja em 2005 e, em 2017, esse percentual cresceu para 42,77 \% (Dados do Ministério da Indústria, Comércio Exterior e Serviços).

Em Cintra e Pinto (2017), além do efeito China sobre o preço das commodities, o papel das estratégias do desenvolvimento chinês, em sua fase mais recente, é examinado inclusive em termos da ampliação do uso de sua moeda (Renminbi) em termos mundiais —incluída, em 2015, pelo FMI na cesta de moedas que compõem os Direitos Especiais de Saque - e dos investimentos de capitais chineses em megaprojetos de infraestrutura transnacional.

No Brasil, articulados às dinâmicas de exportação e, sobretudo, no período pós-crise de 2008, foram previstos e implantados vários projetos de infraestrutura econômica (rodovias, hidrelétricas, portos e minerodutos) no Programa de Aceleração do Crescimento (PAC 1 e PAC 2). Outras estratégias de investimentos em infraestrutura vinculadas ao escoamento de commodities também ocorreram na escala continental sul-americana, através da Iirsa (Iniciativa para Integração da Infraestrutura Regional Sul-Americana). Esses investimentos são coerentes à conformação de um modelo econômico neo-primário-exportador, cujos agentes centrais foram, no período lulista, grandes empresas nacionais e multinacionais do sistema agroalimentar e do complexo minero-metalúrgico, bancos públicos como o BNDES (Banco Nacional de Desenvolvimento Econômico e Social) e empresas estatais como a Petrobrás, articulados em circuitos espaciais de acumulação que vão desde a escala internacional às regionais - continental e subnacional.

Com base nos valores dos contratos do BNDES no período 2007-2014 (Tabela 1) pode-se verificar que 40,5\% deles foram destinados ao hidro, agro e mineronegócio, o que reforça a importância dos setores produtores e exportadores de commodities durante os governos petistas. 
Fernando Michelotti y Hipólita Siqueira

Tabela 1. Operações contratadas pelo BNDES com agentes privados, de forma direta e indireta, não automática, reembolsável, 2007-2014 (em R $\$$ bilhões)

\begin{tabular}{|c|c|c|c|c|c|c|c|c|c|c|c|c|}
\hline & \multirow{2}{*}{2007} & \multirow{2}{*}{2008} & \multirow{2}{*}{2009} & \multirow{2}{*}{2010} & \multirow{2}{*}{2011} & \multirow[b]{2}{*}{2012} & \multirow[b]{2}{*}{2013} & \multirow[b]{2}{*}{2014} & \multicolumn{3}{|c|}{ Total } \\
\hline & & & & & & & & & & $\mathrm{R} \$ \overline{b i}$ & $\%$ & $\%$ \\
\hline \multicolumn{2}{|c|}{ Infraestrutura } & 34,35 & 18,57 & 52,54 & 19,47 & 34,30 & 65,56 & 30,28 & 32,78 & 287,85 & 54,8 & 100 \\
\hline \multicolumn{2}{|r|}{ Energia Elétrica } & 12,32 & 13,60 & 31,19 & 9,23 & 17,81 & 41,39 & 11,84 & 14,79 & 152,18 & 29,0 & 52,9 \\
\hline \multicolumn{2}{|r|}{ (a) Ger. Hidrel. } & 4,64 & 7,05 & 19,28 & 0,99 & 6,23 & 28,38 & 2,16 & 0,90 & 69,63 & 13,3 & 24,2 \\
\hline \multicolumn{2}{|r|}{ (b) Distr. E. El. } & 3,01 & 1,98 & 2,49 & 1,51 & 3,41 & 2,09 & 3,21 & 4,75 & 22,45 & 4,3 & 7,8 \\
\hline \multicolumn{2}{|r|}{ (c) Trans. E. El. } & - & 0,36 & 1,59 & 0,83 & 4,24 & 3,15 & 3,89 & 5,70 & 19,74 & 3,8 & 6,9 \\
\hline \multicolumn{2}{|r|}{ Transporte } & 14,15 & 1,91 & 11,66 & 7,23 & 10,05 & 13,70 & 11,32 & 15,70 & 85,71 & 16,3 & 29,8 \\
\hline \multicolumn{2}{|r|}{ Telecomunicações } & 6,20 & 2,31 & 6,27 & 0,96 & 4,99 & 8,77 & 6,03 & 1,10 & 36,62 & 7,0 & 12,7 \\
\hline \multicolumn{2}{|r|}{ Outros } & 1,69 & 0,75 & 3,43 & 2,05 & 1,44 & 1,70 & 1,09 & 1,19 & 13,34 & 2,5 & 4,6 \\
\hline \multicolumn{2}{|c|}{ Indústria } & 26,56 & 27,14 & 27,38 & 26,42 & 19,47 & 26,00 & 17,94 & 18,06 & 188,97 & 36,0 & 100 \\
\hline \multicolumn{2}{|r|}{ Mat. Transporte } & 5,22 & 1,67 & 4,71 & 9,23 & 3,88 & 6,03 & 5,08 & 2,48 & 38,31 & 7,3 & 20,3 \\
\hline \multicolumn{2}{|r|}{ Química e Petroq. } & 6,76 & 5,27 & 7,21 & 6,29 & 1,95 & 3,32 & 3,92 & 3,94 & 38,67 & 7,4 & 20,5 \\
\hline \multicolumn{2}{|r|}{ (d) Álc. / Bioc. } & 3,88 & 3,07 & 5,12 & 4,25 & 0,38 & 0,43 & 1,47 & 1,85 & 20,43 & 3,9 & 10,8 \\
\hline & (e) Fert./Agr.tx & - & - & 0,17 & 0,38 & 0,23 & 0,10 & 0,06 & 0,06 & 1,00 & 0,2 & 0,5 \\
\hline & Outros & 2,88 & 2,21 & 1,92 & 1,66 & 1,34 & 2,80 & 2,39 & 2,03 & 17,23 & 3,3 & 9,1 \\
\hline & (m)Extrativa & 1,26 & 9,63 & 3,94 & 0,40 & 1,06 & 3,91 & 2,93 & 2,54 & 25,66 & 4,9 & 13,6 \\
\hline & Alimento e Bebida & 2,08 & 3,99 & 3,64 & 1,92 & 3,65 & 3,31 & 1,90 & 2,77 & 23,27 & 4,4 & 12,3 \\
\hline & (f) Açúcar (brt) & 0,65 & 2,22 & 0,80 & 0,07 & 1,11 & 0,98 & 0,68 & 0,63 & 7,15 & 1,4 & 3,8 \\
\hline & (g) Aves e Suín. & 0,79 & 0,51 & 0,34 & 0,78 & 0,22 & 1,09 & 0,17 & 0,22 & 4,13 & 0,8 & 2,2 \\
\hline & (h) Bovinos & 0,03 & 0,43 & 0,43 & 0,26 & - & 0,11 & 0,04 & 0,12 & 1,42 & 0,3 & 0,8 \\
\hline & (i) Óleo e Far. V & - & 0,17 & 0,46 & 0,25 & - & 0,21 & 0,38 & 0,02 & 1,49 & 0,3 & 0,8 \\
\hline & (j) Laticínio & 0,07 & 0,16 & 0,32 & 0,03 & 0,06 & - & 0,07 & 0,19 & 0,89 & 0,2 & 0,5 \\
\hline & Outros & 0,54 & 0,49 & 1,30 & 0,53 & 2,26 & 0,92 & 0,56 & 1,59 & 8,18 & 1,6 & 4,3 \\
\hline & (n)Metalurg. e Prod. & 7,88 & 4,51 & 3,29 & 3,13 & 2,18 & 1,39 & 1,19 & 0,82 & 24,39 & 4,6 & 12,9 \\
\hline & Siderg. Prim. & 6,62 & 1,75 & 0,96 & 1,28 & 0,13 & 0,21 & 0,12 & 0,23 & 11,31 & 2,2 & 6,0 \\
\hline & Outros & 1,25 & 2,76 & 2,33 & 1,85 & 2,05 & 1,17 & 1,07 & 0,59 & 13,08 & 2,5 & 6,9 \\
\hline & (k)Celulose e Papel & 0,26 & 0,10 & 2,15 & 3,10 & 3,91 & 4,93 & 0,80 & 3,78 & 19,03 & 3,6 & 10,1 \\
\hline & Outras & 3,11 & 1,95 & 2,44 & 2,35 & 2,84 & 3,10 & 2,12 & 1,72 & 19,64 & 3,7 & 10,4 \\
\hline Comé & Serviços & 3,03 & 2,39 & 3,79 & 4,48 & 6,62 & 7,39 & 5,43 & 6,85 & 39,99 & 7,6 & 100 \\
\hline (l)Agrc & ecuária & 0,87 & 0,92 & 0,58 & 0,75 & 0,27 & 2,49 & 2,03 & 0,42 & 8,33 & 1,6 & 100 \\
\hline & Produção Florestal & 0,27 & 0,06 & 0,13 & 0,59 & 0,23 & 1,15 & 1,17 & - & 3,59 & 0,7 & 43,1 \\
\hline & Cana-de-Açúcar & 0,14 & - & 0,32 & - & - & 1,19 & 0,87 & 0,25 & 2,77 & 0,5 & 33,3 \\
\hline & Avicultura & 0,37 & 0,79 & 0,06 & 0,12 & - & - & - & - & 1,34 & 0,3 & 16,1 \\
\hline & Outros & 0,10 & 0,07 & 0,07 & 0,04 & 0,04 & 0,15 & - & 0,17 & 0,63 & 0,1 & 7,5 \\
\hline Total & R\$ milhões & 64,81 & 49,01 & 84,29 & 51,12 & 60,66 & 101,44 & 55,68 & 58,11 & 525,13 & 100 & \\
\hline & $\%$ & 12,3 & 9,3 & 16,1 & 9,7 & 11,6 & 19,3 & 10,6 & 11,1 & 100 & & \\
\hline Hidro & gócio $(a+b+c)$ & 7,66 & 9,39 & 23,36 & 3,33 & 13,88 & 33,61 & 9,26 & 11,35 & 111,82 & 52,6 & \\
\hline Agron & ócio $(d+e+f+g+h+i+j+k+l)$ & 6,55 & 7,59 & 10,35 & 9,87 & 6,18 & 10,34 & 5,70 & 7,30 & 63,88 & 30,0 & \\
\hline Miner & gócio $(m+n)$ & 7,88 & 11,38 & 4,90 & 1,67 & 1,20 & 4,12 & 3,05 & 2,77 & 36,97 & 17,4 & \\
\hline Total & R\$ milhões & 22,09 & 28,36 & 38,61 & 14,87 & 21,25 & 48,06 & 18,02 & 21,41 & 212,67 & 100 & \\
\hline & $\%$ & 34,1 & 57,9 & 45,8 & 29,1 & 35,0 & 47,4 & 32,4 & 36,8 & 40,5 & & \\
\hline
\end{tabular}

Fonte: elaboração dos autores a partir de dados do BNDES. Valores deflacionados pelo IGP-DI (dez. 2014). 
Financeirização das commodities agrícolas e economia do agronegócio no Brasil: notas sobre suas implicações para o aumento...

\section{ECONOMIA DO AGRONEGÓCIO, EXPANSÃO DA PRODUÇÃO AGROPECUÁRIA E AGRAVAMENTO DA QUESTÃO FUNDIÁRIA}

A combinação entre elevação dos preços internacionais das commodities e políticas governamentais, em contexto de ascensão da economia do agronegócio, estão relacionadas a alterações significativas da produção agroalimentar brasileira. Além da expansão dos cultivos também houve alteração em sua composição, tendo em vista a crescente participação da área colhida das monoculturas para produção de commodities. Conforme o Gráfico 2, houve aumento expressivo daquelas denominadas como flex crops, que se adequam a diferentes demandas de mercado (alimentação humana, alimentação animal, insumos industriais ou agrocombustíveis). Entre 2000 e 2016, houve crescimento das áreas colhidas de milho (25,8\%), cana-de-açúcar $(112,8 \%$ ) e soja (142,8 \%), o que contrasta com a redução das principais culturas alimentares do país, cuja área colhida diminuiu em 47 \% (arroz), 40,4 \% (feijão) e $17,7 \%$ (mandioca).

Gráfico 2. Brasil: Crescimento da área colhida de culturas vegetais, 1990-2016, em hectares $(2000=100)$

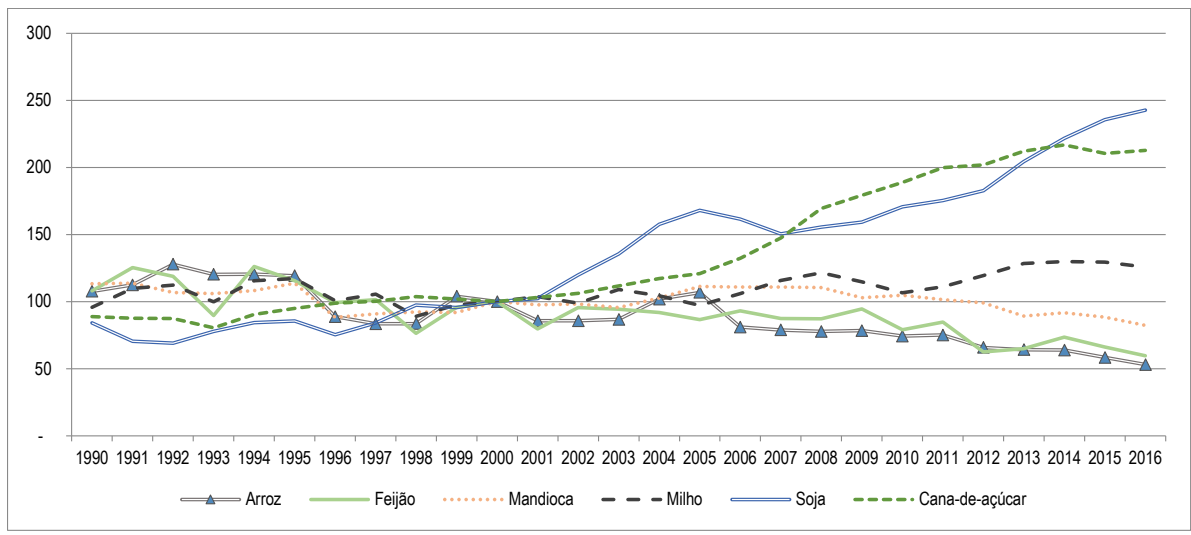

Fonte: elaborado pelos autores a partir de dados do IBGE/PAM (Produção Agrícola Municipal), vários anos.

A expansão dos monocultivos de exportação acarreta mudanças mais profundas que vão além da área plantada e colhida. Sauer e Leite (2012) refletem sobre a expansão das duas principais commodities agrícolas brasileiras, cana-de-açúcar e soja, e sugerem que nessas áreas, assim como nas de plantios industriais de árvores e mineração, houve ampliação dos investimentos (de capital nacional e estrangeiro), em diferentes partes do processo produtivo, inclusive na fase primária e na compra de terras. Relacionado a esse processo, verificou-se um aquecimento do mercado de terras com elevação dos preços. 
Ao analisar a evolução do preço da terra no Brasil e considerar diferenças regionais e de tipo de uso, a partir de diferentes fontes de dados, Bacha, Stege e Harbs (2016) indicam uma queda nos preços das terras iniciado em 1994, que se prolongou até 1999, seguido de uma ascensão a partir de 2000. Tal ascensão foi heterogênea, tanto em termos regionais como em termos de usos da terra, e foi mais significativa nas terras de lavoura do que nas de pastagens.

Utilizando os mesmos dados desses autores, pode-se estimar o seguinte crescimento de preços entre jun/2000 e dez/2014: a) terras de lavouras tiveram um crescimento de 149,3\% na média nacional (de $\mathrm{R} \$$ 4.763,65/ha para $\mathrm{R} \$ 11.874,73$ / ha), na região Sul o preço por hectare chegou a R\$ 19.663,54 e b) nas terras de pastagens, o crescimento passou de $\mathrm{R} \$ 2.294,20$ /ha para $\mathrm{R} \$ 5.825,36 /$ ha, o que representa crescimento percentual de $153,9 \%$. O maior crescimento percentual ocorreu na região Centro-Oeste, com 272,9 \% nas terras de lavoura e 239,4 \% nas terras de pastagens.

Ao aprofundarem a análise do mercado de terras brasileiro durante o boom das commodities, Flexor e Leite (2017) percebem que não apenas houve uma ampliação na aquisição de terras, inclusive com capital estrangeiro, mas também uma alteração na lógica patrimonial e produtiva. Em outros períodos, a inversão de capitais em terra no Brasil expressava objetivos indiretos, tais como o acesso ao sistema nacional de crédito rural ou como lastro para a segurança do capital em contexto de instabilidade econômica e inflação. O período atual mostra mudanças qualitativas nos tipos de inversão, pois, como demonstram esses autores, houve, nesse período, uma correlação negativa entre preço da terra e inflação. Por outro lado, houve uma forte correlação positiva entre preço da terra e preços das commodities e demais índices do mercado financeiro. Isso, por sua vez, indica que esses investimentos estão mais relacionados aos interesses produtivos e de especulação com a terra do que à formação de reserva de valor, tal como na trajetória histórica do país.

Ainda conforme Flexor e Leite (2017), essa dinâmica gerou enormes benefícios para as grandes corporações do agronegócio, tanto internacionais como nacionais. Grupos internacionais, tais como ADM, Bunge, Cargill e Dreyfus, ampliaram sua ação acompanhando o deslocamento da produção para as novas regiões de expansão e se diversificaram para novas frentes de produção, por exemplo, de agrocombustíveis. Além disso, uma série de aquisições e fusões apoiadas por recursos do BNDES marcou o sistema agroalimentar brasileiro, tanto no setor agrícola (Amagi, Coama e Caramuru), como no setor animal, com a emergência de empresas nacionais de grande porte (JBS, Marfrig e BRF Foods). 
Financeirização das commodities agrícolas e economia do agronegócio no Brasil: notas sobre suas implicações para o aumento...

Essas dinâmicas de modificação da produção de commodities brasileiras, em especial, daquelas ligadas ao agronegócio, inserem-se em um quadro mais geral da questão agrária nacional. Baseado no processo de internacionalização da agricultura brasileira, Alentejano (2014) aponta quatro temas nucleares da questão agrária brasileira no início deste século: i) persistência da concentração fundiária e várias desigualdades daí decorrentes; ii) crescente insegurança alimentar; iii) perpetuação da violência e da exploração do trabalho e iv) devastação ambiental. Com relação ao primeiro tema, da concentração fundiária, Sauer e Leite (2012) analisam a expansão das commoditites e elevação do preço da terra como vetores de complexificação e aprofundamento dos conflitos agrários, tanto por causa da dificuldade do Estado em implementar políticas de reforma agrária diante do aumento do interesse econômico e político das frações do capital pela terra como do agravamento das lutas populares pela (re)conquista da terra ou resistência em face das expulsões.

Esse fenômeno não é especificamente brasileiro e tem sido categorizado na literatura por termos tais como land grabbing ou acaparamiento de tierras, cuja tradução para o português apresenta certas dificuldades não apenas por problemas semânticos, mas, segundo Sauer e Borras (2016), pela disputa de sentidos políticos e ideológicos envolvidos nessa tradução. Para esses autores, o termo começou a ser traduzido como "aquisição de terras em larga escala por estrangeiros" e/ou "estrangeirização da terra", que se mostram insuficientes diante da complexidade do fenômeno. Nessa perspectiva, defendem a tradução para o termo "apropriação de terras", relacionado aos conceitos de acumulação e expropriação/espoliação não apenas de terras, mas também dos recursos naturais que estas contêm (água, minérios e biodiversidade).

Condizente com essa perspectiva, Borras et al. (2013) argumentam que, sobretudo no caso da América Latina, o acaparamiento de terras envolve três fatores inter-relacionados: i) a concentração do controle da terra, que permite mudanças nas formas de uso e no seu significado/fenômeno relacional e político, expressão de relações de poder; ii) transferência de controle em grande escala, não tanto em termos de área física, mas de capital envolvido; iii) vinculação aos imperativos da acumulação de capital, em especial dos novos centros de acumulação, tais como países do BRICS (Brasil, Rússia, Índia, China e África do Sul).

A partir disso, esses autores argumentam que o acaparamiento de terras na América Latina não se resume à apropriação de terras por capitais e Estados estrangeiros, e chamam atenção para a atuação (direta e indireta) de capitais e Estados nacionais, inclusive com aporte financeiro e legitimação. Ao abordar a dominação da terra em termos de controle político, não restringem a análise aos processos de compra/ expropriação e incluem inúmeros outros mecanismos, tais como arrendamentos de 
curto e longo prazo, contratos e joint ventures, o que indica que, além da expulsão de produtores locais, existem outras formas de subordinação em curso. Por fim, sugerem que o acaparamiento não ocorre apenas no setor alimentar e nem como resposta exclusiva aos aumentos dos preços desses produtos, mas envolve diversos setores agrícolas e não-agrícolas, cada qual com seus mecanismos específicos de vinculação à especulação financeira.

Gráfico 3. Brasil expansão territorial da produção de cana-de-açúcar, soja e pecuária bovina entre 2000-2016

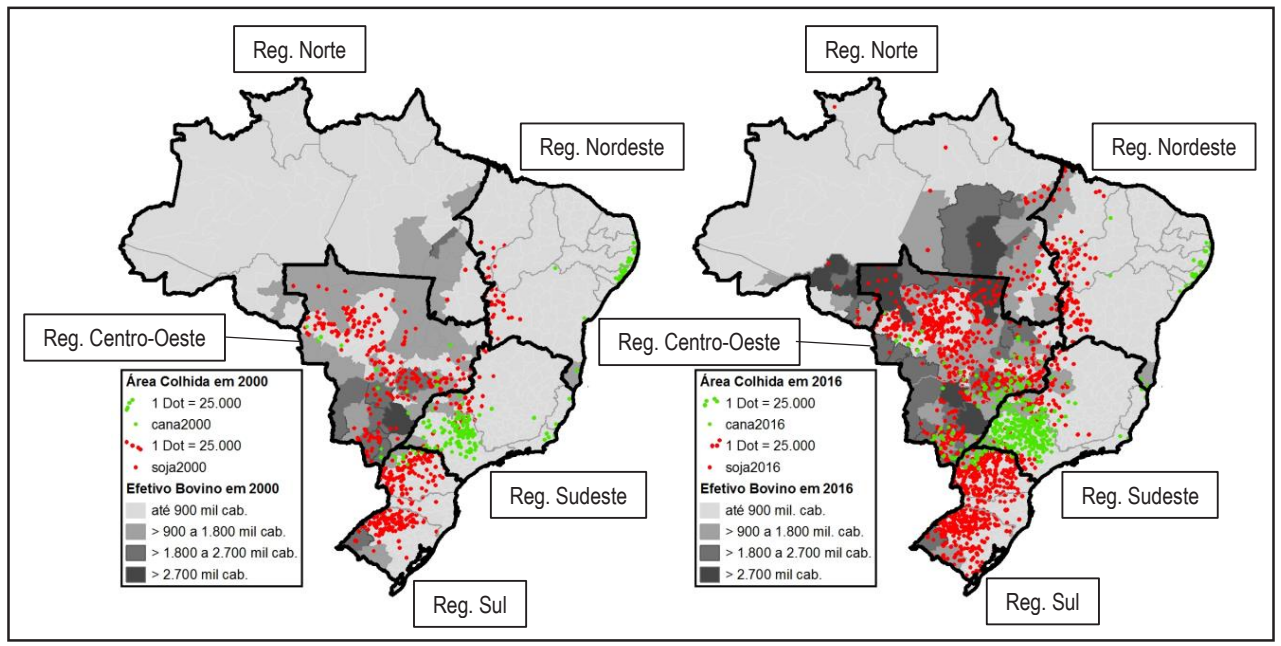

Nota: cana-de-açúcar e soja: área colhida em ha./bovinos: efetivo do rebanho (mil cabeças).

Fonte: elaboração dos autores a partir de dados do IBGE/PAM (Produção Agrícola Municipal) e PPM (Pesquisa Pecuária Municipal) $(2000,2016)$.

O Gráfico 3 é ilustrativa da expansão territorial da cana-de-açúcar, soja e da pecuária no Brasil. De acordo com os dados anuais do IBGE, a área colhida total com cana-de-açúcar, cujo aumento entre 2000 e 2016 foi de 112,8 \% (de 4,8 para 10,2 milhões de ha), ampliou sua concentração no estado de São Paulo (Região Sudeste), que passou de 51,7 \% para 54,7 \% da área colhida nacional. No caso da soja, cuja expansão total foi de 143,0 \% (com a área colhida aumentando de 13,7 para 33,2 milhões de ha), houve três áreas principais de expansão: nos tradicionais estados plantadores, na região sul do país, que, no entanto, reduziu sua expressão de 44,5 \% para 34,8 \% da área colhida nacional; nas fronteiras de expansão na Região Centro-Oeste, que saltou de 40,5\% para 44,0 \% da área colhida (aumento de 169,4\%); nas novas fronteiras em direção às regiões Norte e Nordeste que aumentaram sua participação de 6,6 \% para 11,2 \% do total nacional (aumento de 310,0). Por fim, a pecuária mostra uma concentração nas áreas circundantes à expansão da soja nessas 
Financeirização das commodities agrícolas e economia do agronegócio no Brasil: notas sobre suas implicações para o aumento...

fronteiras do Centro-Oeste e Norte-Nordeste, tanto em função das possibilidades de instalação de agroindústrias de abate e processamento de carne beneficiadas pelos investimentos em infraestrutura de transporte, energia e comunicação compartilhados com a produção de soja como por um deslocamento das pastagens em função da ocupação de antigos pastos com os grãos. A dinâmica soja-pecuária atua, assim, como um dos principais vetores de expansão da fronteira agropecuária em direção à Amazônia (Região Norte) e configura um território em expansão que apresentou um crescimento de $46,3 \%$ do rebanho, contra um crescimento de $28,5 \%$ do rebanho nacional, e que passou de uma participação de 50,5 \% para $57,6 \%$ desse total.

No Gráfico 4, a seguir, podem ser visualizados mapas que demonstram a concentração de terras e conflitos territoriais nesses complexos do agronegócio. No Mapa 2 (a), podem ser observados os três complexos territoriais do agronegócio citados anteriormente: complexo da cana-de-açúcar em São Paulo; complexo da soja na Região Sul e complexo da soja-pecuária de fronteira que envolve a Região Centro-Oeste e partes das regiões Norte e Nordeste. No mapa 2 (b), pela projeção dos dados de Hoffmann e Ney (2010) sobre desigualdade na distribuição da terra nos estados brasileiros (índice de Gini), fica clara a assimetria na distribuição de terras no país. Apenas 9 entre 27 Unidades da Federação (26 estados + Distrito Federal) apresentaram redução do Gini entre 1995 e 2006. Além disso, desses que apresentaram redução, seis mantiveram o índice acima de 0,82. No complexo da cana-de-açúcar de São Paulo, houve elevação do Gini para 0,803, enquanto nos estados do complexo da soja-pecuária de fronteira, 55,6 \% tiveram aumento do Gini e 77,8 \% apresentaram índices em 2006 acima de 0,80.

O Mapa 2 (c), construído com os dados preliminares do Censo Agropecuário de 2017, revela que, além da desigualdade na distribuição, há concentração fundiária, expressa na elevada porcentagem de ocupação das terras por estabelecimentos com 500 ha ou mais que, no conjunto do país, representam apenas 2,1 \% do número total de estabelecimentos com alguma área. Chama atenção que na maio r parte dos estados que compõem o complexo da soja-pecuária de fronteira, com exceção de Rondônia, todos encontram-se nos dois quartis superiores em relação à porcentagem de ocupação de terras por estes grandes estabelecimentos agropecuários, o que reforça a associação entre expansão do agronegócio e concentração fundiária. Também nesses estados, conforme o Mapa 2 (d), predominaram os maiores quantitativos de ocorrências de conflitos por terra na fase de agravamento entre 2009 e 2016, o que sugere que há relações diretas entre concentração fundiária e conflitos por terra. Essa situação também se dá em São Paulo, com a expansão canavieira, e no extremo sul, com a expansão de grãos. 
Gráfico 4. Concentração de terras e conflitos territoriais nos complexos do agronegócio

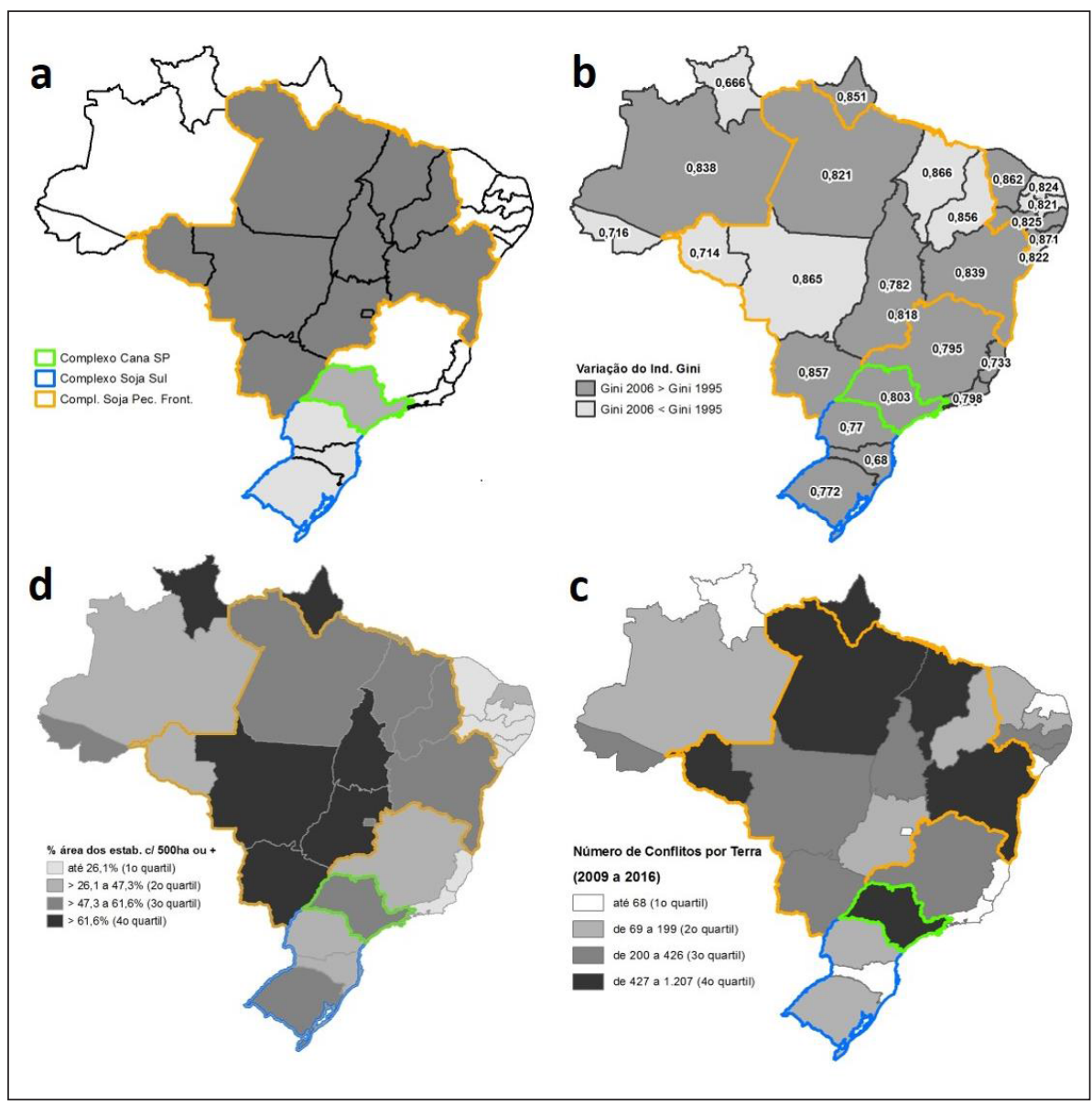

Fonte: elaboração dos autores a partir dos seguintes dados: (a) do IBGE/PAM (Produção Agrícola Municipal) e PPM (Pesquisa Pecuária Municipal) (2000, 2016); (b) Hoffmann e Ney (2010); (c) IBGE - Censo Agropecuário 2017 (dados preliminares); (d) Comissão Pastoral da Terra - Caderno Conflitos de Campos (vários anos).

Dados da Comissão Pastoral da Terra (CPT) indicam que de um máximo de 1.398 conflitos em 2004 e 1,127 milhão de pessoas envolvidas em 2003, houve uma redução até 2008, que chegou a um número de 751 conflitos e 354.225 pessoas envolvidas. Após isso, nos anos seguintes, ainda durante os governos petistas, os conflitos voltaram a crescer e chegaram a 1.018 conflitos em 2014, que envolveram 600.240 pessoas e se agravaram após o impeachment de Dilma Rousseff em 2016, quando alcançaram 1.295 conflitos, que envolveram 686.735 pessoas e 23,7 milhões de hectares (CPT, 2017). 
Financeirização das commodities agrícolas e economia do agronegócio no Brasil: notas sobre suas implicações para o aumento...

Esses conflitos, expressão da desigualdade e concentração de terras associada à expansão do agronegócio, devem ser entendidos como parte de uma persistente tendência na dinâmica socioespacial brasileira de utilização da dimensão territorial tanto como busca de novos espaços de acumulação como de acomodação de conflitos. As estratégias de colonização de fronteiras, largamente utilizadas durante a Ditadura Militar (1964-1985), como forma de amenizar as tensões agrárias da modernização agropecuária, foram em grande medida, reproduzidas nos anos recentes através de diferentes políticas governamentais. No entanto, assim como naquela época, esse tipo de tentativa acaba por reproduzir na fronteira as contradições presentes nas regiões de origem, isso gera novos conflitos entre camponeses migrantes, fazendeiros, empresas, indígenas, frações do campesinato e oligarquias locais, o que começou a ficar evidente após 2008.

Esse deslocamento geográfico para a fronteira explica a mudança no perfil dos envolvidos na maior parte dos conflitos agrários nesse período, que passou do campesinato sem-terra do Centro-Sul para as chamadas populações tradicionais da Região Norte, em lutas que assumiram o caráter de disputas territoriais. Refletese, também, no aumento da extensão das áreas envolvidas em conflitos agrários, que passaram de 1,9 milhões de hectares em 2000 para 13,2 milhões de hectares em 2012, máximo valor durante os governos petistas (Michelotti, 2014).

Essas análises estão em consonância com as de Almeida et al. (2010) de que o fortalecimento econômico e político dos setores produtores e exportadores de commodities do agronegócio e da mineração deu-se através de uma articulação bastante particular entre formas intensivas e extensivas de acumulação. Em ambas, ganhos decorrentes do aumento da produtividade, da intensificação do trabalho e da aceleração da rotação do capital associam-se à expropriação de recursos comunais e especulação financeira e imobiliária, na cidade e no campo. Nessa mesma perspectiva, Acselrad e Barros (2013, p. 19) afirmam que, no campo brasileiro, a frente intensiva de acumulação busca ganhos de rendimento por hectare por meio da intensificação das condições de exploração do trabalho rural e do uso crescente de insumos industriais, enquanto a frente extensiva "requer a incorporação de novas áreas, produtivas ou especulativas, pela expropriação de terras ocupadas por pequenos produtores, terras públicas, áreas de reserva legal, terras indígenas ou de povos tradicionais".

\section{CONCLUSÕES}

A partir das notas apresentadas neste artigo sobre o debate teórico relativo ao regime de acumulação contemporâneo, foram destacadas as relações entre os determinantes dos mercados secundários e as mudanças nos mercados das 
commodities, em geral, e das agrícolas, em específico. São importantes as tendências que revelam uma dinâmica vinculada aos mecanismos e lógicas de operação dos mercados financeiros que, associadas a um contexto geoeconômico e geopolítico impactado pela forte demanda chinesa de matérias-primas, insumos e alimentos, levam a uma forte valorização desses produtos. Tais processos inter-relacionados potencializam uma corrida por terras no mundo, e isso mobiliza países e regiões com abundância de terras, recursos naturais e com histórico de pactos de dominação política favoráveis às lógicas de acumulação rentistas e patrimoniais.

No caso brasileiro, uma maior complexidade dos ciclos de valorização dos preços das commodities está associada à consolidação de uma economia do agronegócio que vem sendo gestada desde os anos 1990. A combinação de políticas governamentais favoráveis a esta, em um contexto de boom dos preços das commodities e aumento da demanda internacional, levou à expansão da pecuária e do cultivo de soja e cana-de-açúcar, altamente intensivas em recursos naturais, em detrimento dos produtos tradicionais da alimentação brasileira (arroz, feijão e mandioca). Os dados apresentados indicaram movimentos territoriais caracterizados por intensa incorporação de terras tanto em regiões de fronteira agropecuária como em regiões industrializadas do país. O aquecimento e a valorização dos preços no mercado de terras expressam esse movimento crescente de apropriação territorial.

Todos esses elementos podem ser associados à uma complexificação da questão agrária no Brasil, cujo resultado tem sido a manutenção da concentração fundiária e a agudização das desigualdades na apropriação da terra. Se o fortalecimento da economia do agronegócio esteve associado a estratégias de combate à pobreza com alguma influência na redução dos conflitos agrários até 2008, o caráter territorialmente expansivo da produção agropecuária e a ausência de uma política redistributiva impediu uma redução de mais longo prazo, o que explica a retomada do crescimento dos conflitos.

\section{BIBLIOGRAFIA}

Acselrad, Henri e Barros, Juliana Neves (2013). Os Descaminhos da Associação entre o 'Senhor Capital' e a 'Senhora Terra'. Em: CPT - Comissão Pastoral da Terra Conflitos no Campo Brasil, 2012. CPT - Nacional: Goiânia, Brasil, p. 18-24

Alentejano, Paulo (2014). Questão Agrária e Agroecologia no Brasil do século XXI. Em: Molina, Mônica Castagna et al. (org.) Práticas contra-hegemônicas na formação dos profissionais das Ciências Agrárias: reflexões sobre questão agrária e agroecologia no Brasil do século XXI. NEAD: Brasília, Brasil, p. 23-57.

Almeida, Alfredo Wagner B. de; Zhouri, Andrea; Ioris, Antônio A. A. R.; Brandão, Carlos; Bermann, Célio; Hernández, Francisco del Moral; Bezerra, Gustavo das N.; Acselrad, Henri; Paula, João 
Financeirização das commodities agrícolas e economia do agronegócio no Brasil: notas sobre suas implicações para o aumento...

A. de; Laschefski, Klemens; Coelho, Maria C. N.; Monteiro, Maurilio de A.; Garzon, Luís F. N.; Cunha, Luís H. e Wanderley, Luiz J. (2010). Apresentação. Em: do Nascimento, Humberto (Org.) Capitalismo Globalizado e Recursos Territoriais: fronteiras da acumulação no Brasil contemporâneo. Editora Lamparina, Rio de Janeiro, Brasil, p. 7 8.

Bacha, Carlos José Caetano; Stege, Alysson Luiz e Harbs, Ricardo (2016). Ciclos de Preços de Terras Agrícolas no Brasil. Em: Revista de Política Agrícola, vol. 25, n. ${ }^{\circ} 4$, outubro-dezembro, p. 18-37.

Borras Jr., Saturnino M.; Kay, Cristóbal; Gomez, Sergio e Wilkinson, John (2013). Acaparamiento de tierras y acumulación capitalista: aspectos clave en América Latina. Em: Revista Interdisciplinaria de Estudios Agrarios, n. ${ }^{\circ} 38,1^{\circ}$ semestre, p. 75-103.

Carneiro, Ricardo; Rossi, Pedro; Chilliato Leite, Marcos Vinicius e Mello, Guilherme Santos (2011). A quarta dimensão: os derivativos em um capitalismo com dominância financeira. Em: IE/ Unicamp - Texto para Discussão (Campinas), n. ${ }^{\circ}$ 199, dezembro, p. 1-32.

Chesnais, François (2005). A finança mundializada: raízes sociais e políticas, configuração, consequências. Boitempo: São Paulo, Brasil, 255p.

Cintra, Marcos Antonio Macedo e Pinto, Eduardo Costa (2017). China em transformação: transição e estratégias de desenvolvimento. Em: Revista de Economia Política, vol. 37, n. 2, abriljunho, p. 381-400. DOI: http://dx.doi.org/10.1590/0101-31572017v37n02a07

CPT —Comissão Pastoral Da Terra— (2017). Conflitos no Campo — Brasil 2016. Goiânia, Brasil, CPT Nacional, 232p.

Delgado, Guilherme Costa (2012). Do Capital Financeiro na Agricultura à Economia do Agronegócio: mudanças cíclicas em meio século (1965-2012). Ed. da UFRGS: Porto Alegre, Brasil, 142p.

Flexor, Georges e Leite, Sérgio P. (2017). Land Market and Land Grabbing in Brazil during the Commodity Boom of the 2000s. Em: Contexto Internacional, vol. 39, n. 2, maio-agosto, p. 393-420. DOI: http://dx.doi.org/10.1590/s0102-8529.2017390200010

Guttmann, Robert (2016). Finance-led capitalism: shadow banking, re-regulation, and the future of global markets. Palgrave Macmillan: New York, 268p.

Harvey, David (2005). O Novo Imperialismo. Ed. Loyola: São Paulo, Brasil, 201 p.

Harvey, David (2008a). A Condição Pós-Moderna: uma pesquisa sobre as origens da mudança cultural. Ed. Loyola: São Paulo, Brasil, 349p.

Harvey, David (2008b). O Neoliberalismo: história e implicações. Ed. Loyola: São Paulo, Brasil, $256 p$.

Hoffmann, Rodolfo e Ney, Marlon Gomes (2010). Estrutura fundiária e propriedade agrícola no Brasil, grandes regiões e unidades da federação. Ministério do Desenvolvimento Agrário: Brasília, Brasil, 108p.

Kerckhoffs, Thijs; van Os, Roos e Vander Stichele, Myriam (2010). Financing Food: Financialisation and Financial Actors in Agriculture Commodity Markets. Em: SSRN Electronic Journal, 11p. DOI: http://dx.doi.org/10.2139/ssrn.1597138 
Michelotti, Fernando (2014). Resistência camponesa e Agroecologia. Em: Molina, Mônica Castagna et al. (org.) Práticas contra-hegemônicas na formação dos profissionais das Ciências Agrárias: reflexões sobre questão agrária e agroecologia no Brasil do século XXI. NEAD: Brasília, p. 60 87.Paulani, Leda (2008). Brasil Delivery: servidão financeira e estado de emergência econômico. Boitempo: São Paulo,150p.

Rubio, Blanca (2015). El Dominio del Hambre: crises de hegemonia y alimentos. Universidad Autónoma Chapingo - Colegio de Postgraduados / Universidad Autónoma de Zacatecas / Juan Pablos Editor: México, 279p.

Sassen, Saskia (2016). Expulsões: brutalidade e complexidade na economia global. Paz e Terra: São Paulo, 336p.

Sauer, Sérgio e Borras Jr., Saturnino M. (2016). 'Land Grabbing' e 'Green Grabbing': uma leitura da 'corrida na produção acadêmica' sobre a apropriação global de terras. Em: Campo-Território: revista de geografia agrária, vol. 11, n. ${ }^{\circ}$ 23, p. 6-42. DOI: http://dx.doi.org/10.14393/RCT112301

Sauer, Sérgio e Leite, Sérgio P. (2012). Expansão Agrícola, Preços e Apropriação de Terra por Estrangeiros no Brasil. Em: RESR, Piracicaba-SP, vol. 50, n. ${ }^{\circ}$ 3, p. 503-524. 